Korb S., Sacks R., and Alhava O. (2017). “A Portfolio/Process/Operations (PPO) Analysis of a Meta-project Production System in Renovation Projects” In: LC3 2017 Volume II - Proceedings of the 25th Annual Conference of the International Group for Lean Construction (IGLC), Walsh, K., Sacks, R., Brilakis, I. (eds.), Heraklion, Greece, pp. 161-168. DOI: https://doi.org/10.24928/2017/0322

\title{
A PORTFOLIO/PROCESS/OPERATIONS (PPO) ANALYSIS OF A META-PROJECT PRODUCTION SYSTEM IN RENOVATION PROJECTS
}

\author{
Samuel Korb ${ }^{1}$, Rafael Sacks ${ }^{2}$, and Otto Alhava ${ }^{3}$
}

\begin{abstract}
The Portfolio/Process/Operations (PPO) model is a novel approach to understanding the elements that impact production systems in the world of construction. Building on prior work such as the "Transformation-Flow-Value" (TFV) theory, the PPO model adds a multi- and meta-project view through its consideration of the total "Portfolio" of projects and partners in which each company in the industry is engaged.

Fira Palvelut is a Finnish contractor specializing in the refurbishment of bathrooms in the aging Finnish mass housing market. This paper examines Fira's efforts to improve their operations and finds that by addressing each of the elements of the PPO model, they have managed to build a robust and successful production system that dramatically outpaces the industry standard for project lead time. In the renovation sphere, this means customers must be out of their houses for significantly less time while the work is performed.

In this paper, we give a background to the PPO model and Fira Palvelut's operations, and analyze their success through the lens of each element of the model.
\end{abstract}

Keywords: Lean construction, PPO model, case study, linked projects

\section{INTRODUCTION}

The Portfolio/Process/Operations (PPO) model is a new approach to conceptualizing the intertwined factors that impact the work flow in construction production systems (Sacks, 2016). "Operations" are the individual value-adding tasks performed by trade crews, while "Process" reflects the flow of individual products (locations within a building project) through the tasks across different trades. "Portfolio" introduces a meta-project point of view, by examining how general contractors schedule the flow of their projects, considering building projects as product units. The portfolio and the operations levels are linked to close a loop, in that the trade crews (subcontractors and suppliers) balance the demands of the multiple projects in which they are involved across the local construction market.

Fira $\mathrm{Oy}$ is a Finnish construction contractor. Among other lines of business, Fira offers bathroom-renovation services to aging housing projects, in which the bathrooms in a multi-floor building are refurbished, including replacement of all of the plumbing systems and most of the electrical. After completing a number of projects in this domain using a traditional planning and control model - i.e. by subcontracting each of the demolition,

PhD Student, Faculty of Civil and Environmental Engineering, Technion - Israel Institute of Technology, Haifa, Israel, shmuel.korb@technion.ac.il

2 Associate Professor, Faculty of Civil and Environmental Engineering, Technion - Israel Institute of Technology, Haifa, Israel, cvsacks@technion.ac.il

3 Otto Alhava, M.Sc. (Tech.), Chief Technology Officer, Fira Group Oy, Vantaa, Finland, otto.alhava@fira.fi 
plumbing systems, electrical systems, mechanical systems, concrete and block work, and tiling work to separate sub-contracted crews and managing them using a critical path method plan - Fira was able to identify and quantify much of the wastes in the system.

Fira then applied Lean thinking to the problem and has devised a new approach in which it views individual bathrooms as products in a production system which spans across buildings and projects. On the basis of this conceptual change, the system attempts to build a predictable work pace and flow which extends from project to project in a carefully planned portfolio. Similarly, the subcontractors are aligned using Alliancing agreements and other similar contract structures, which allow them to take a meta-project view of their work flow and avoid periods of under-utilization between projects. Though Fira did not explicitly set out to implement the PPO model (as it was only advanced recently), their practice and their success incorporate the principles of the PPO model of production flow in construction.

In the following sections, we review the PPO model in detail, describe Fira's approach to bathroom renovation, and discuss the degree to which Fira's construction production system can be considered an exemplar of the PPO model. The conclusions provide insight into the domains within construction and the ways in which the PPO model can be applied in practice.

\section{THEORETICAL BACKGROUND}

The PPO model is based on the 'Process-Operation' conceptual distinction made by Shingo (1988) between the work tasks done on successive products at the same work station (the operation axis) and the successive sequence of tasks that each product flows through as it moves through the company (the process axis). In the case of construction, the PPO model recognizes that the product is stationary and the work stations (trade crews) flow through the product (Sacks, 2016). The construction products are the locations (room, apartment, floor, or any other distinct zone that is handed over to a customer). The locations are built along the process axis, whereas the trade crews work on the operations axis.

This same conceptual framework underpins the Location-Based Management approach which uses a "Line of Balance" chart to manage (both planning and control) the progress of construction projects (Kenley and Seppänen, 2006). A Line of Balance (LOB) chart portrays the locations of the construction project on the $\mathrm{Y}$ axis and the progress of time on the $\mathrm{X}$ axis. The locations move through time and through the trades, on the Process axis. Each trade is portrayed as a line moving through the locations, along an Operations axis. This is shown graphically in Figure 1.

The contribution of Shingo's model was to broaden the scope of attention given by managers and industrial engineers beyond merely the work transpiring at each work station, where focus naturally gravitates, and instead to look at the work through the "eyes" of the product to identify the journey it took through the manufacture and supply process. This approach underlay much of the work done to improve processes at Toyota, where Shingo was one of the thought leaders behind the Toyota Production System, and is a key component of Lean thinking to this day. Koskela (2000) also highlighted this distinction in his "Transformation-Flow-Value" (TFV) theory (in which Transformation corresponds to Operations and Flow corresponds to Process). TFV added an additional element, Value, as a way of viewing the work activities through the eyes of the customer.

In construction, there is a third element - construction is a form of project production rather than factory or serial production (Ballard, 2005). The PPO model encompasses this aspect by adding a third dimension - the project Portfolio. Projects can be considered 
products in and of themselves, and one can conceptualize the flow of a company's construction projects using notions such as work in progress (the number of projects a company is engaged in simultaneously) and cycle time (the duration of each project). As such, theoretical constructs such as Little's law can be applied. Figure 2 illustrates the three dimensions.

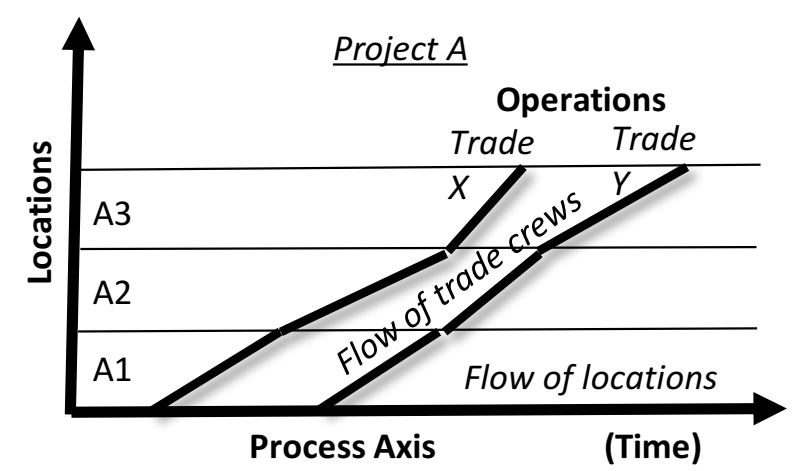

Figure 1: Traditional "Line of Balance" (LOB) chart for managing a single project, showing Process (location) flows and Operations (trade crew) flows.

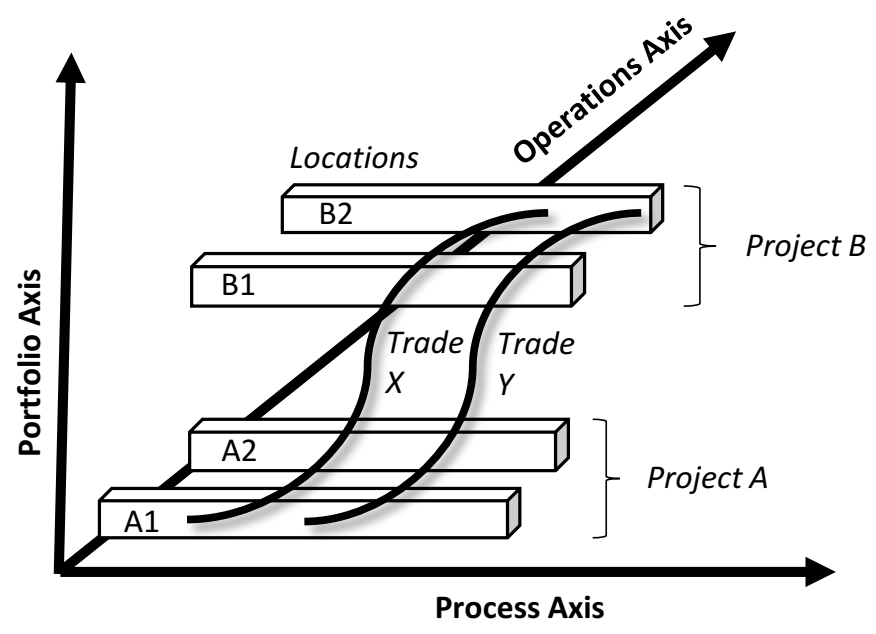

Figure 2: Three-dimensional Portfolio, Process and Operations (PPO) model of construction flows.

Furthermore, in the construction industry, it is common for the actual work to be carried out by subcontractors who can work at more than one project at a time for more than one General Contractor. As Sacks and Harel (2006) have shown, the inter-project dynamic for a subcontractor who is juggling the demands of multiple projects can have a significant impact on the progress of a given project. Thus in the same way that the work must be viewed through the eyes of the product, it must also be viewed through the eyes of the multi-site resources, if global optimization and favorable project outcomes are to be pursued. The cyclical nature of the PPO model is shown in (a)

(b)

Figure 3b. 


\section{Fira Palvelut Oy}

Fira Oy was founded in 2002, working first as a concrete subcontractor, and growing quickly to become a general contractor. Today Fira Group Oy has a staff of some 240 employees and an annual turnover that exceeds $€ 130 \mathrm{M}$. Fira has long been devoted to innovative methods in construction management, such as Building Information Modeling, the Last Planner ${ }^{\circledR}$ System, early contractor involvement in the design process, Alliancing, process standardization, a Lean-inspired focus on removing waste and managing the process (as opposed to managing by results), and use of an "Obeya" or "Intensive Big Room" for collaborative design processes (Alhava et al., 2015). In 2015, the company created a subsidiary called Fira Palvelut, which focuses on bathroom renovations (see Figure 4).

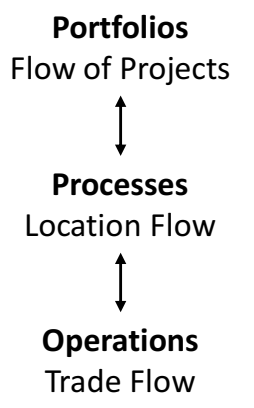

(a)

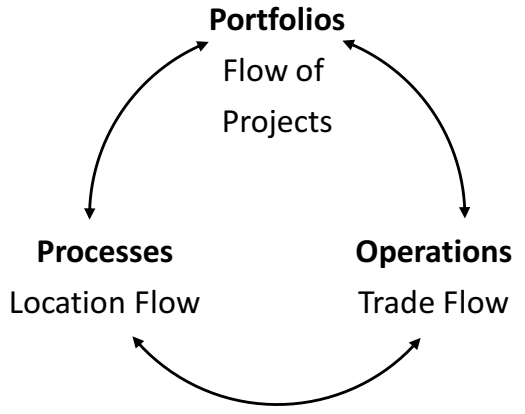

(b)

Figure 3: Hierarchical (a) vs. cyclical (b) relationships in the PPO model. The cyclical view reflects the flow of trades across projects as well as their flow across locations within a project.

While the market Fira Palvelut focuses on is narrow, the potential size of that niche is large given the dynamics of the Finnish housing market. In the 1950s and 1960s, Finland had a wave of mass-housing building projects. Today, the plumbing in those projects is reaching the end of its service lifespan, which means that many buildings require complete retrofits of their bathrooms and plumbing. The typical ownership structure is a homeowner's association which owns the entire building, meaning the "customers" for renovation projects are the building management companies, each with tens or even hundreds of units (as opposed to individual tenants contracting their own renovations).

Fira Palvelut has focused on two main concepts: flow and value. The former, flow, grew out of their realization of the magnitude of the waste in the processes. A video recording of a typical renovation showed that during $82 \%$ of the working hours from the beginning of work to the end of work in an apartment, the apartment was empty, and the remaining $18 \%$ was filled with other wastes including lots of unnecessary movement. With a 13-week customer lead time (time the customers would have to move out of their house while work was underway), the thought was by doing no more than getting rid of the waiting time, they could cut the customer lead time to a fraction of the current amount.

The latter concept, value, was a harder lesson to internalize, since sometimes the interests of the customer were not seen to overlap with those of the company (in terms of honouring any and all requests, etc.). But a customer-value focus was crucial to build the volume of work that they would need to improve the production processes. Indeed, Fira now offers each individual customer the ability to customize their new bathroom, even though the variation this creates complicates the job Fira has to do (in terms of managing 
information and the supply chain). Furthermore, each project has a service engineer whose sole job is to serve the needs of the tenants. The short lead-time and customized product have given them a competitive edge in their market.

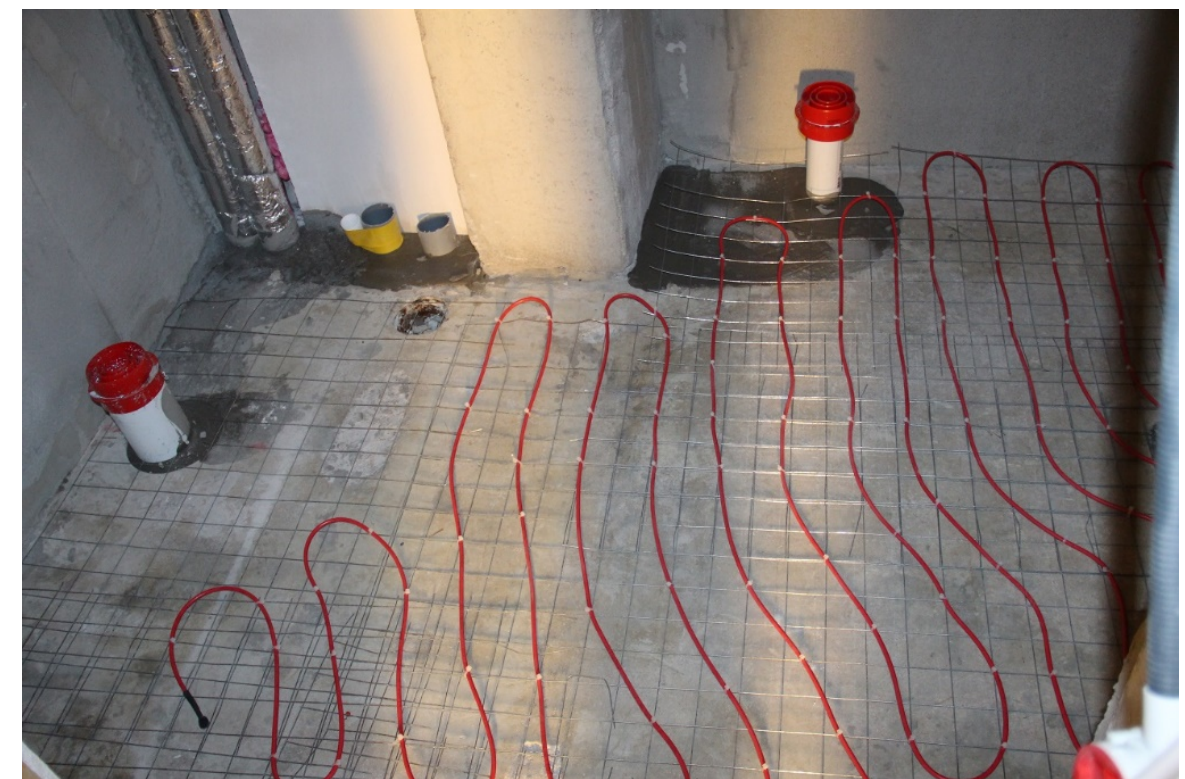

Figure 4: Typical bathroom, post-demolition, with tubing laid for in-floor heating

Fira's key innovation to improve flow has been to create stable groups of subcontractors called "trains" that move together from project to project. In each project, the "coaches" of the train proceed from apartment to apartment at designated intervals (a form of Takt planning). Capacity buffers (in the form of overtime or temporarily adding workers) are used to maintain consistency in the cycle times, so that the coaches do not become uncoupled and nor does the train derail. In this way, they were able to reduce customer move-out duration from thirteen weeks to a standard of five weeks, and consequently to grow the business almost six-fold in the course of five years. A pilot program has reduced the apartment cycle-time further, to two weeks, which garnered attention in the local press.

\section{PPO AT FIRA}

In building the unique production system that is Fira Palvelut, Fira has instinctively addressed all of the elements of the PPO model, and in so doing, they have harnessed the synergy that can be created when those elements are in harmony.

\subsection{Portfolio}

One of the key things that Fira has done is work to create a stable backlog of projects, so that when one project is finished, the next is immediately ready to start. In this way, they are able to provide the crews with a steady supply of jobs, and in return they ask that the subcontractors maintain the crew composition from project to project (as a comparison, in prior projects less than $10 \%$ of the crew members would continue from one project to the next). In essence, they are aware of the crucial importance of the "Portfolio" from the point of view of the subs and thus take active steps to make sure that it is addressed (by providing a dependable flow of projects).

For subcontractors, the continuity of projects is a boon, since it avoids gaps between projects, gaps that are problematic due to the fixed costs for the subcontractor and 
questions about whether to hold onto or lay off their staff. The workers can also be affected by discontinuities in the work; if they know that there is no new project in the pipeline after the current one (which could mean no work for weeks or months), they may be subject to psychological pressures (knowingly or not) which could slow the pace of work.

As is apparent from the model and the example provided by Fira's practical experience, understanding these meta-project dynamics at work is crucial to the efficient management of any given project and the many client-service provider relationships it contains, because it guides thinking toward establishment of streams of projects that provide for optimal trade-crew flows both within a project and from project to project. By addressing the portfolio-level interests of all agents and designing production systems accordingly, better outcomes can be achieved for all parties.

In turn, through Alliancing agreements and other similar contract structures, Fira gains high-quality work and some measure of control over which specific workers are involved in each project. This allows them to build on the learning curve of each individual project, accumulating learning from project to project instead of starting from scratch with each new project team (compare the ad-hoc approach in Figure 5 to the continuous flow of projects in Figure 6). This directly enables continuous improvement.
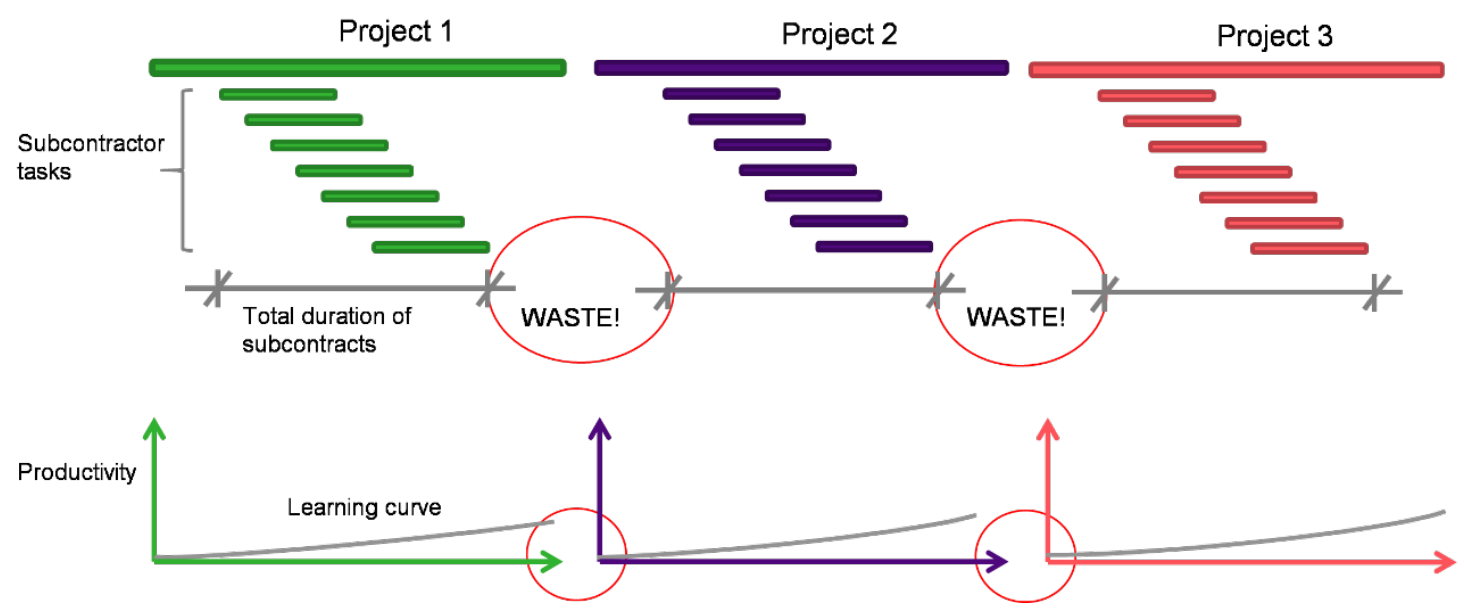

Figure 5: The "waste" of shared learning when projects are disconnected and teams are ad-hoc

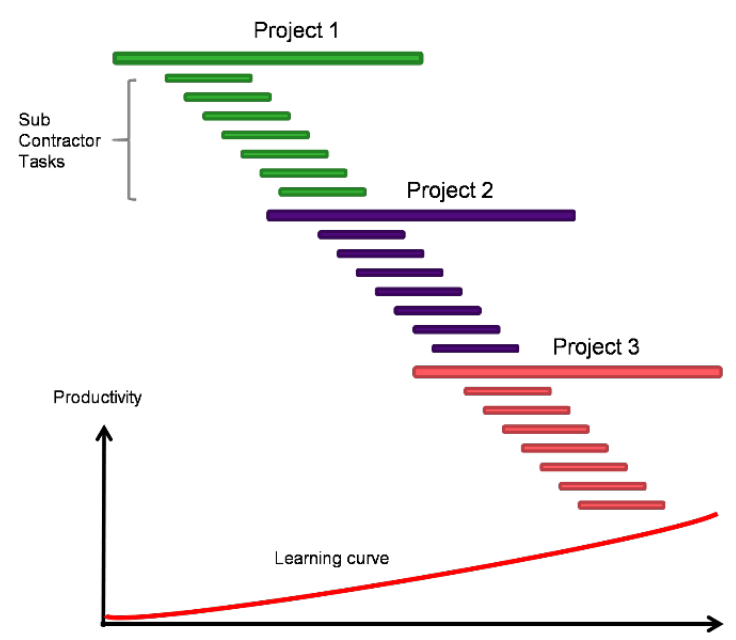

Figure 6: Linking projects and maintaining team continuity leads to long-term learning and improvement 


\subsection{Process}

The key enabler to building a stable flow of work both within and between projects has been a keen attention to Process. This meant identifying, quantifying, defining, and balancing the work packages so that each coach of the train has an equal duration of work. The continuity of personnel from project to project provided by the attention to Portfolio was crucial to the improvement of the processes, since there was a set team who could be engaged in the joint Value Stream Mapping (VSM)-type work required to examine the work flow and jointly coordinate their actions. Rather than arriving to each new site and having to renegotiate their working relationships (if they exist at all) with the other subs, the workers in the Fira Palvelut model are part of a quasi-organization that has intentional longevity. As Priven and Sacks (2016) have shown, growing the social interactions between the team members has positive impacts on project outcomes.

The stability that is gained in the work durations has been leveraged to compress project timelines, an effective competitive advantage in a market niche that requires residents to find alternate accommodations during the refurbishment. All of this comes from an awareness of the existence of a work process that involves all of the trades and a conscientious drive to identify and remove the wastes that impede the smooth flow.

One example was the acquisition of a diamond drill by the demolition team. Previously, the demolition subcontractor had hired another company to drill the holes in the concrete necessary to run the new plumbing. But the wait for an exterior party, coupled with the motivation on the part of the driller to wait until a batch of works had built up, was causing interruptions to the flow which were having negative impacts on the overall work. The demolition team eventually purchased their own drill so they could self-perform that part of the work, on time, as needed, in batches as arbitrarily small as the flow required. Fira systematically documents these innovations as they are implemented and standardizes them across projects, though developing standardized processes across the trains remains a challenge.

\subsection{Operation}

Connecting project to project with the same team has an additional benefit at the level of the individual Operations. The continuity it provides means that there is a degree of repetition not present in the typical one-off project organization. Continuous improvement is based upon being able to stabilize processes, which often means having a sufficient degree of repeatability of the operation under study. In a here-today, gonetomorrow traditional project, the interest in investing in continuous improvement (to say nothing of the underlying repetition that is necessary) rapidly approaches zero. But in a scenario where the crews are doing roughly the same work from day to day, project to project, with the same suppliers and other crews they are interfacing with, the situation is completely different. Suddenly there is not only room for improvement but also desire, since the benefits will be paid out for as long as the trains keep moving from project to project. This happened with the electrical crew, who were able to drop their costs by $18 \%$ under their estimation by focusing on improving from project to project.

\section{CONCLUSIONS}

The success of Fira is a good indication of how the elements of the PPO model are interconnected, as depicted in Figure 3b. Their attention to the "Portfolio" element allows improvements to both Process and Operation, which in turn have benefits to the overall 
Portfolio of the parties concerned. And indeed, the meta-project element is a key innovation, both in the PPO model and in Fira's practice.

One critique of Fira's practice is that their Location Breakdown Structure (LBS) does not go down to the individual apartment level, thus stopping short of the Lean "One Piece Flow" ideal. This is due to the nature of the local construction market, where the ownership structure is as described above (leading to entire buildings hiring Fira), and where subfloor components of each bathroom are actually located in the apartment below so that each 'entrance' (typically with some 10-20 apartments) is the smallest planning unit. In other markets, the logical implication of the PPO model is to reduce the product to the smallest indivisible unit (the apartment). But as the case of Fira shows, this ideal can be influenced by the prevailing cultural, technological, and legal context.

In conclusion, Fira's practice illustrates implementation of a production system that considers all three aspects of the PPO model. The designers of Fira's production system are implicitly aware of all elements: of the project portfolio, of the process undergone by each individual apartment, and of the operations performed by the trade crews. They have addressed each in an integrative fashion to improve performance. By building a continuity of projects, the portfolio of each of the partners is being given its due, instead of the typical one-off approach leaving each of the members of the ad-hoc construction organization to fend for themselves at project end. Furthermore, the continuity allows attention to be given to improving both the individual operations and the overall flow, creating balanced work sequences which are themselves crucial to scheduling each trade and each project.

\section{REFERENCES}

Alhava, O., Laine, E., Kiviniemi, A., 2015. Intensive big room process for co-creating value in legacy construction projects. J. Inf. Technol. Constr. ITcon 20, 146-158.

Ballard, G., 2005. Construction: One Type of Project Production System, in: 13th Annual Conference of the International Group for Lean Construction. University of New South Wales, Sydney, pp. 29-35.

Kenley, R., Seppänen, O., 2006. Location-Based Management for Construction: Planning, Scheduling and Control. Routledge.

Koskela, L., 2000. An Exploration towards a Production Theory and its Application to Construction. (Dissertation for the degree of Doctor of Technology). Helsinki University of Technology.

Priven, V., Sacks, R., 2016. Impacts of the Social Subcontract and Last Planner System Interventions on the Trade-Crew Workflows of Multistory Residential Construction Projects. J. Constr. Eng. Manag. 04016013. doi:10.1061/(ASCE)CO.1943-7862.0001102

Sacks, R., 2016. What constitutes good production flow in construction? Constr. Manag. Econ. 34, 641-656. doi:10.1080/01446193.2016.1200733

Sacks, R., Harel, M., 2006. An economic game theory model of subcontractor resource allocation behaviour. Constr. Manag. Econ. 24, 869-881. doi:10.1080/01446190600631856

Shingō, S., 1988. Non-stock production: the Shingo system for continuous improvement. Productivity Press, Cambridge, Mass. 